\title{
Capstone - Rules of Engagement
}

\section{Dr. Afroditi Vennie Filippas, Virginia Commonwealth University}

Dr. Filippas received her B.S. in Electrical Engineering from the University of Patras, Greece. After earning her M. S. and Ph. D. from the University of Texas at Austin, she completed post-doctoral research with the Institute of Accelerating Systems and Applications in Athens, Greece. Post-academically, she worked for Ansoft Corporation as a research scientist spearheading the development of the next generation code for Ansoft DesignerTM. Dr. Filippas joined Virginia Commonwealth University as an Assistant Professor in the School of Engineering in 2004. She went on to achieve the position of Associate Professor and Associate Chair of Electrical and Computer Engineering in 2008. In 2010, Dr. Filippas agreed to serve as interim associate dean of undergraduate studies in the School of Engineering. Dr. Filippas was appointed to the position of associate dean of Undergraduate Studies in 2015, and was promoted to Professor in August, 2016. In this role, she is responsible for all aspects of the undergraduate program. She provides vision and leadership in achieving the School's objectives for substantial growth in the size and quality of its undergraduate enrollment while maintaining its commitment to excellence in undergraduate engineering education. Focus areas include contemporary teaching and learning technologies, capstone, special degree programs with partnering academic institutions, and K-12 outreach. Dr. Filippas is especially proud of her collaboration with NSBE at VCU, an organization that embodies excellence in academics as well as community service, leadership and diversity. In addition, Dr. Filippas was instrumental in establishing oSTEM on the campus as well as reaching out to other underrepresented minority groups to further the university's commitment to student success and inclusive excellence.

\section{Prof. Umit Ozgur, Virginia Commonwealth University}

Umit Ozgur received his B.S. degrees in Electrical Engineering and Physics from Bogazici University (Turkey) and PhD degree in Physics from Duke University in 2003. He joined the Department of Electrical and Computer Engineering at VCU in 2008 as an Assistant Professor following postdoctoral researcher and instructor positions at Duke University and VCU. He was awarded the Qimonda Endowed Professorship in 2012, and received Parent's Award for Excellence in Undergraduate Teaching in 2012 and Faculty Excellence Award for excellence in teaching in 2014. He has made contributions to the understanding of ultrafast carrier dynamics in semiconductor heterostructures and light emitters, with over 100 journal articles including several critical reviews, 4 book chapters, and a book on Zinc Oxide materials and devices. His current research interests include development of semiconductor heterostructures and nanostructures for high efficiency light emitting devices and biosensors. 


\title{
Capstone: Rules of Engagement
}

\author{
Afroditi V. Filippas and Ümit Özgür \\ Department of Electrical and Computer Engineering, Virginia Commonwealth University, Richmond, VA 23284
}

\begin{abstract}
The execution of the Capstone project at Virginia Commonwealth University's School of Engineering is one of the most intense educational experiences for the student teams and their instructors/mentors. For many students, it is the first time they work one on one with a professor and the first time their entire grade relies on their performance on one project that is executed over such a long period of time. In addition, for many, it is the first time their performance on a team is directly observed and evaluated for aspects such as teamwork, personal contribution and ability to sustain a long-term, congenial relationship with each other and with their professor. To be successful, students need to develop the characteristics of a life-long learner, develop project planning and team dynamics coping mechanisms, combine and apply problem solving skills, and strike the balance between demonstrating independent thinking and exhibiting what the fivefactor model (FFM) calls the "agreeableness" trait [1] [2] [3]. For the professor, very often there is little control over the team composition and no guarantee that the team will be able to sustain good work habits and healthy team dynamics for the entirety of the experience. At our institution, the projects culminate in a Capstone Expo that is attended by an audience ranging in skill sets and interests from Middle and High School students to industry partners, industry experts, engineering students and faculty and students from around the university. This paper will cover all the above aspects of the Capstone experience up to and including preparing the team for the Expo.
\end{abstract}

\section{Keywords}

Capstone, teamwork, $21^{\text {st }}$ century skills, design, interdisciplinary

\section{Background}

Capstone at our institution is organized fairly consistently across departments. Faculty members take on one or more teams and supervise them through a year-long experience to project completion. The projects, spread across two semesters, earn the students 4 credits and are required to involve construction of a novel device/system which meets appropriate engineering standards and multiple realistic constraints. Over the course of the academic year, students hone their skills through team meetings, brainstorming sessions, designing, simulating, fabricating and assembling their concepts as well as reviewing, researching and validating their designs. Projects in the Electrical and Computer Engineering department are organized along broad categories including Computer Engineering (Advanced Digital Design), Communications, Controls, and Advanced Microscale and Nanoscale Fabrication. The current paper will outline the experiences and lessons learned from the perspective of the two authors who, either collaboratively or independently, have supervised over 20 capstone projects in the last eight years. The methods employed to lead these teams to a successful conclusion of their projects are consistent with good design practices as well as robust team management principles. 


\section{The projects}

Depending on the origin of the project, capstone projects fall under three general categories. They can be defined (1) through an external agency - a non-profit or an industry partner, (2) by the faculty advisor or (3) by the students themselves. Partnering with industry on the capstone experience has granted many important benefits; in addition to the additional funding, this has provided students the opportunity to work directly with industry advisors as well as to work on a project that is relevant to that industry. Student-inspired projects on the other hand have the advantage of built-in buy-in from the team members. It is important to note, however, that neither scenario mitigates the need for the faculty advisor to be highly engaged and to implement a methodical approach to tackling the capstone project that places equal emphasis on the academic as well as the practical objectives of this endeavor.

Table 1: Capstone project-general requirements.

\begin{tabular}{l|l|}
\hline Requirement & Details \\
\hline Novelty & This could be in the design, the concept, the approach, or the analysis \\
\hline Rigor & $\begin{array}{l}\text { This refers to the level of expertise the students need to develop in order } \\
\text { to achieve a successful outcome, as well as the scientific methodology. }\end{array}$ \\
\hline Potential impact & $\begin{array}{l}\text { This could be to health, the environment, the cost, etc., or to a } \\
\text { combination. }\end{array}$ \\
\hline Good fit & $\begin{array}{l}\text { The relevant expertise, preparation, and facilities have to exist within the } \\
\text { School of Engineering. }\end{array}$ \\
\hline Meet educational & $\begin{array}{l}\text { Develop research, design, analysis, simulation and optimization } \\
\text { experience; Manage team dynamics; Improve verbal and written } \\
\text { communication skills; Apply engineering standards and multiple realistic } \\
\text { constraints. } \\
\text { This involves: } \\
\text { Student Practice: Apply what was learned in courses } \\
\text { Learning/training opportunity: learn new concepts and develop new skills } \\
\text { Practice creativity }\end{array}$ \\
c, d, g, h, j [4]
\end{tabular}

General project requirements, regardless of origin, are shown in Table 1. The challenge when projects are organized independently of each other is in establishing consistent project quality and outcomes. The following sections will outline the system we have established on our teams that helps us motivate all the students to perform well, alleviates or neutralizes team conflicts, and provides a systematic approach to training the students to develop effective timelines without stifling their creativity and in fact stimulates their self-sufficiency. 


\section{Team formation and potential tensions}

This is possibly the aspect of Capstone over which we have the least control. In fact, one could posit that if we could control this aspect of the project, then the efficacy of our method would be dependent on this step to such a degree that its applicability to any team would be suspect. We would like to point out potential conflicts (tensions?) regarding team formation and means to mitigate them. As described above, there are three general ways teams form at our school and specifically within our department. In the student-inspired projects, students usually selfassemble and secure an advisor, while in the industry or faculty-inspired projects, they choose from advertised projects either in teams or individually.

Regardless of the method of team formation, we find that tensions may arise due to:

1. Academically weaker students placed or self-selecting into a team with stronger students,

2. Team being composed of students who have different degrees of buy-in or sense of responsibility for project outcomes,

3. Incomplete teams - all of the necessary skills and/or expertise may not be present in the team, which is of greater concern particularly for the interdisciplinary projects.

4. Poor time-management skills. The team projects students have completed prior to the capstone had much smaller scopes, the outcomes were more well-defined and possibly broken up into stages for the students and almost all teams were engaged in designing the same working prototype.

5. Unfamiliarity with professional interaction with a faculty member. By its nature, the working relationship between the faculty member and the student team is more intimate than when the students are in a classroom. This can develop into a sense of camaraderie that is actually detrimental to the project if it is not managed properly.

6. Additional challenges with the interdisciplinary teams:

a. Project is organized in a "sequential" way - one discipline initiates and is responsible for completing the initial stage of project. If this is not done in a timely manner, students from the other discipline might not be given enough time to implement their part of the project. Time management as well as enabling the students to engage in the project in cross-functional ways is key in this situation.

b. Students of one discipline do not appreciate the contributions of the other discipline; alternatively, they tend to think in very structured ways about their respective disciplines and do not appreciate and take advantage of the overlap and complementary skill sets that exist between disciplines. 
As advisors of long standing of teams that have, at one time or the other exhibited at least one, but more often a combination, of the above traits, we have developed the following philosophy to address team tensions before they arise [3] [4] [5].

1. Immediately address the fact that team conflicts may be inevitable and reduce them to just one more challenge that needs to be met as part of the capstone. This will help alleviate their significance.

2. Emphasize the expectation of $100 \%$ responsibility from each team member. That is, that no matter how many members the team has, they are all $100 \%$ responsible for the project outcome.

3. Set up and maintain expectations for the working relationship between the students and the faculty advisor(s). In our case, this is done by establishing ourselves as the "Director(s)", as in an industrial setting. In this way, we acknowledge the different nature of the dynamic between ourselves and the students while reminding them that we have the responsibility to evaluate their performance throughout this experience. It also sets the stage for how we establish the reporting structure as well as the self- and peer evaluations.

4. Discuss the syllabus and the expectations rubric in terms of an "employee evaluation"; in an industry environment, these would be the goals of the project as well as expectations of individual employee performance and attitude towards the task at hand as well as towards their colleagues. The rubric is more qualitative than quantitative, emphasizing attitude rather than project milestones.

5. Provide students with literature addressing team dynamics, project planning, etc. Students are very good at focusing on the task at hand and performing research on their topic of interest, but many have not yet recognized the necessity of addressing these other issues, or even realized that there is a methodical approach to working on a team with diverse personalities, work habits and skill sets.

\section{Project planning:}

Students need to engage immediately with mapping out their project and projecting it out to completion. Again, it is important for advisors to acknowledge immediately the factors that traditionally trip up teams:

1. Not enough research and brainstorming in the beginning. Students want to "hit the ground running" and do not appreciate that they need to take the time to do some research, exhibit curiosity, and be willing to engage in broad thinking so that they can come up with a robust but flexible plan of attack.

2. Too much research and brainstorming in the beginning. Some teams find it hard to disengage from the research and brainstorming part of their project. It is important to set time limits to all these activities so that they move into the implementation stage within a reasonable time period. 
3. Teams are too optimistic about the amount of time they can spend on the project during the semester. They also don't acknowledge the anticipated need and difficulty of working during long breaks.

4. The inherent difficulty of planning out a long-term project when the team lacks the fundamental understanding (at least in the beginning) of what the necessary components and inherent challenges of the project will be.

Advisors need to be engaged in project planning and keeping students on task until they build up the capacity for this themselves. This is the area where students need the most help. Advisors can help them be effective time managers by demonstrating to them how to take advantage of their deadline-driven nature, but also being honest about their expectations regarding working through Thanksgiving, winter and spring breaks.

Students are also not experienced with adaptable timelines. In class, timelines and deadlines are preset for all assignments and tests. Design projects typically are completed on a much shorter time scale. In a long-term, detailed and innovative project such as the capstone, it is unrealistic to expect students to develop a rigid and detailed timeline. Thus, they need to be trained to start with known, high-level goals and the one truly rigid deadline: Capstone Expo at the end of April. Advisors can also help the team by having them add other known milestones and tasks to their timeline. For example, preparing the midterm report, the final report, and the poster (deadline is three weeks before the Expo), and submitting the project white paper for supplemental external funding through an established grant (mid-November), etc. Students can then use these milestones to establish high-level deadlines for their project, as shown in Figure 1. Note that the timeline template initially developed by the students lists the final goal first, and works backwards.

Teams report weekly through a PowerPoint presentation with three parts, as shown in Figure 2. An important aspect of this exercise is to ensure students are comparing their accomplishments to their proposed timeline and also provides the impetus for the faculty to guide the students in updating their timelines, thus educating them on the concept of adjustable timeline and agile thinking.

Once the students have been shown how to think long-term and then fill in the short-term goals, they quickly learn to develop realistic timelines and work on adjusting them according to up-todate understanding of the challenges and the specific requirements of their project. By meeting regularly with their advisor(s) and reviewing their work relative to the agreed-upon timeline, they are able to gauge their progress realistically and add detail to or change their timelines, always keeping in mind the intermediate requirements and the final deadline. Thus, students are trained to think independently, take control of their own progress and develop a dynamic approach to project planning. 


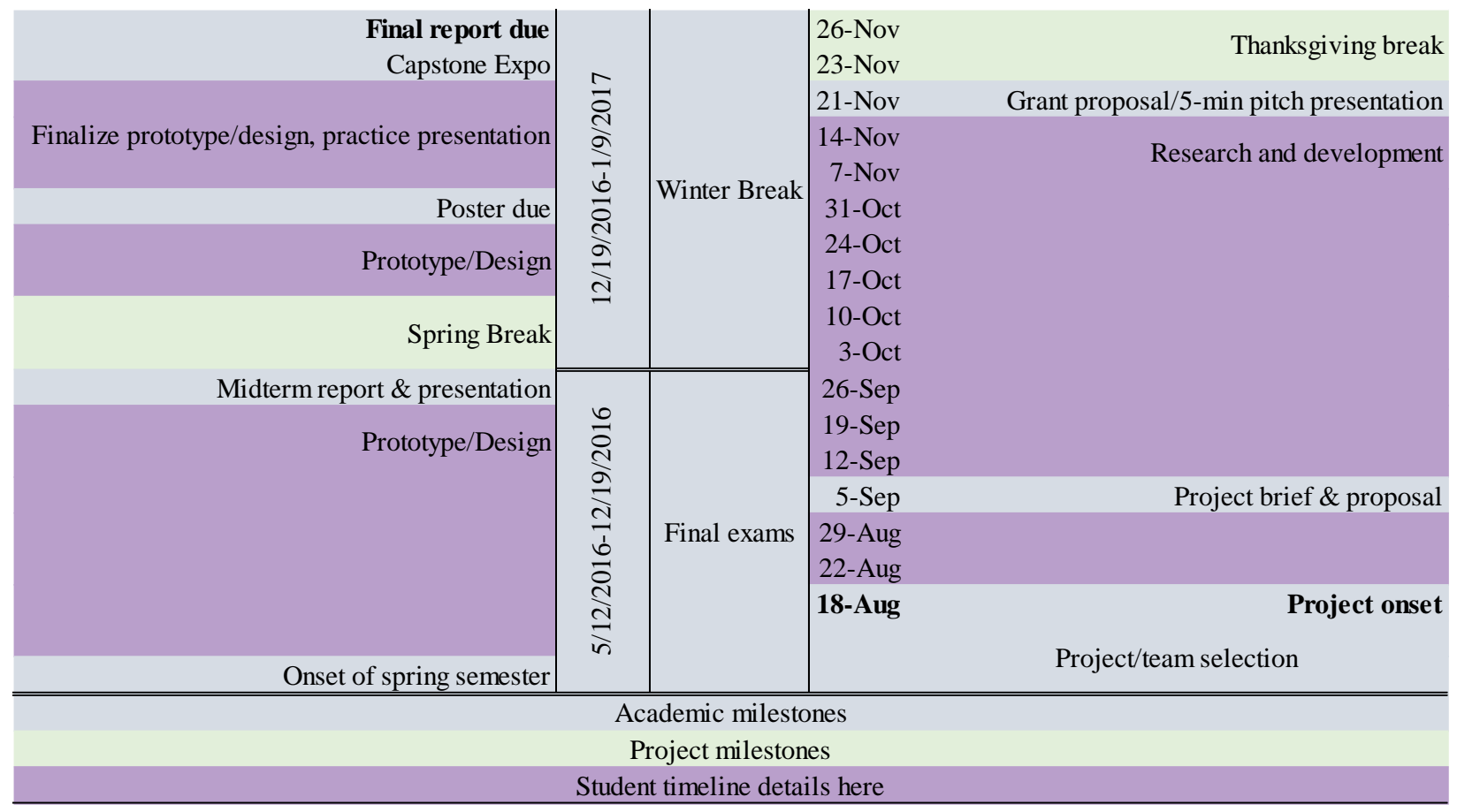

Figure 1: Initial timeline provided to students. Teams are encouraged to use this as a starting point to develop their own timelines. We start them as the end point. This helps them by teaching them to identify long-term and short-term externally-imposed milestones that provide initial guidelines for their own project planning.

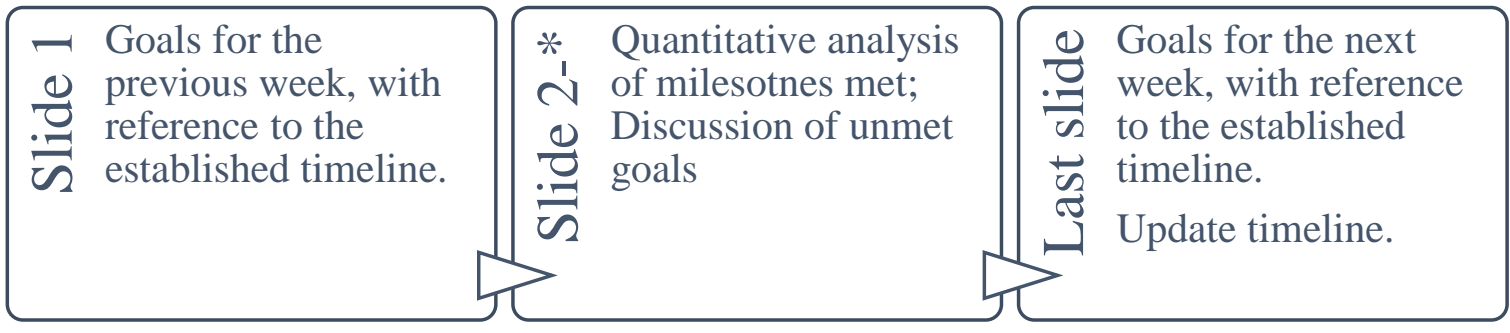

Figure 2: Weekly reports to faculty and industry advisors. Should take no more than 15 minutes, with discussion and brainstorming to follow.

\section{Managing team expectations}

We will discuss here three team characteristics that we feel most heavily impact team dynamics and/or team success.

Team diversity: This could be along technical lines or along racial or gender lines. While our institution is quite diverse - $15 \%$ underrepresented minority and $25 \%$ female - what we are examining here is the technical diversity, where students are put together to work on a project that requires diverse backgrounds. Good examples of this type of projects are the two Mechanical and Nuclear Engineering projects that required the participation of Electrical Engineering students. 


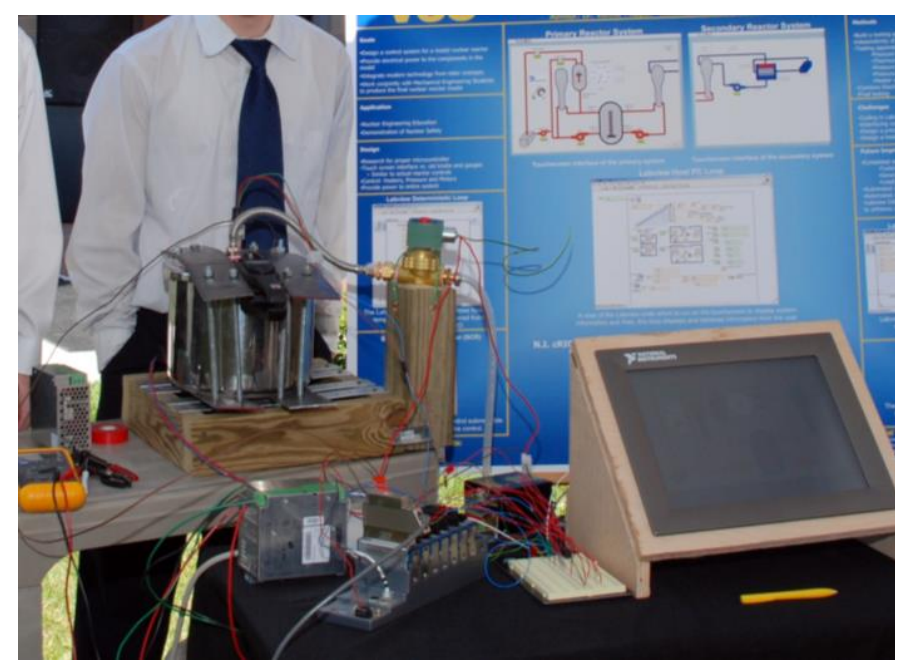

Figure 3: Year one of Visible Reactor project. The ECE students demonstrate the operation of their control system on a repurposed pressure cooker.
In the first project, which was to build a visible "nuclear" reactor prototype, a faculty member from Mechanical Engineering reached out to the Electrical Engineering department to recruit students who could handle the electrical aspects of the project. However, he did not really have a clear idea of what else the Electrical Engineering students could bring to the project other than making electrical connections and designing the circuitry. Fortuitously, the students were required to report to an ECE faculty member. Having a strong support system - a faculty member that spoke on their behalf - enabled the students to participate in every aspect of the project, including helping to develop the infrastructure for the visible reactor. By being proactive and proposing a plan and strategy for its design, they were also put in charge of developing the control system for the reactor, so their involvement gained in significance.

The ECE students, however, faced a major challenge in this project: to design a control system, the infrastructure for the reactor needed to be built, secure, and operational. These requirements were met only close to the end of the spring semester, too late to install and test the control system. Not having the anticipated test environment early in the spring semester, these students diverted their energy to repurposing a pressure cooker, on which they installed a heating element, one pressure sensor and two temperature sensors (Figure 3). They could thus demonstrate the operation of their control system for a nuclear reactor while the ME students demonstrated the mechanical aspects of the visible reactor, which became functional very late in the semester.

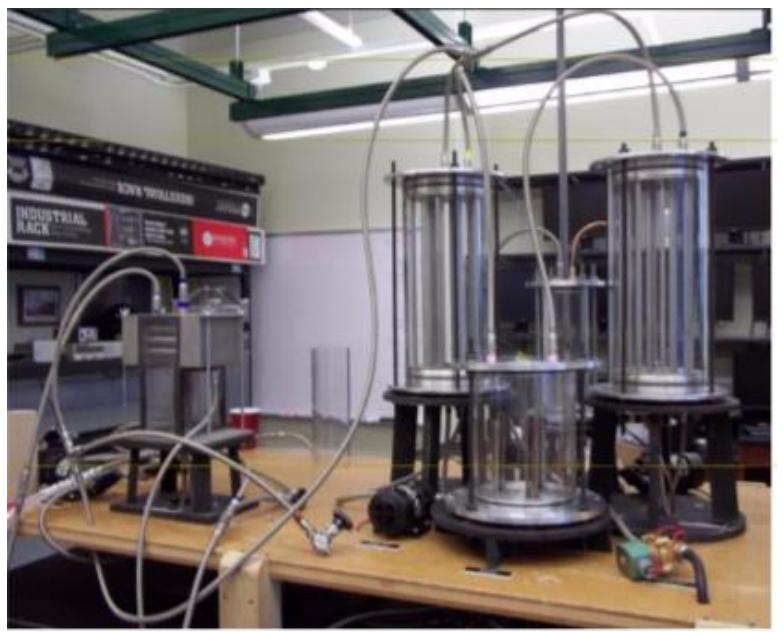

Figure 4: Year two of Visible Reactor project, with control system installed.
It took a second multidisciplinary team and another year to combine the two systems (Figure 4). The project extended over four years and occupied mechanical, electrical and computer engineers. It has now been converted to a successful Master's level project.

In a connected project, electrical engineering students were invited to join a team for designing a nuclear simulator to be used in safety training and for demonstration purposes (Figure 5). Again, the mechanical engineering students came in with the preconceived idea that the electrical engineering students were merely there to set 
up the computer system with the eight screens necessary to implement their code. While the ECE students did do this, they also took a leadership role in suggesting LABVIEW to simulate the controls and were involved in developing the numerical simulations necessary to describe the operation of the nuclear reactor. The experience was rewarding for the mechanical and electrical engineering students, as the mechanical engineers received much stronger support for their project than they were expecting and the electrical engineering students became equal partners in the enterprise.

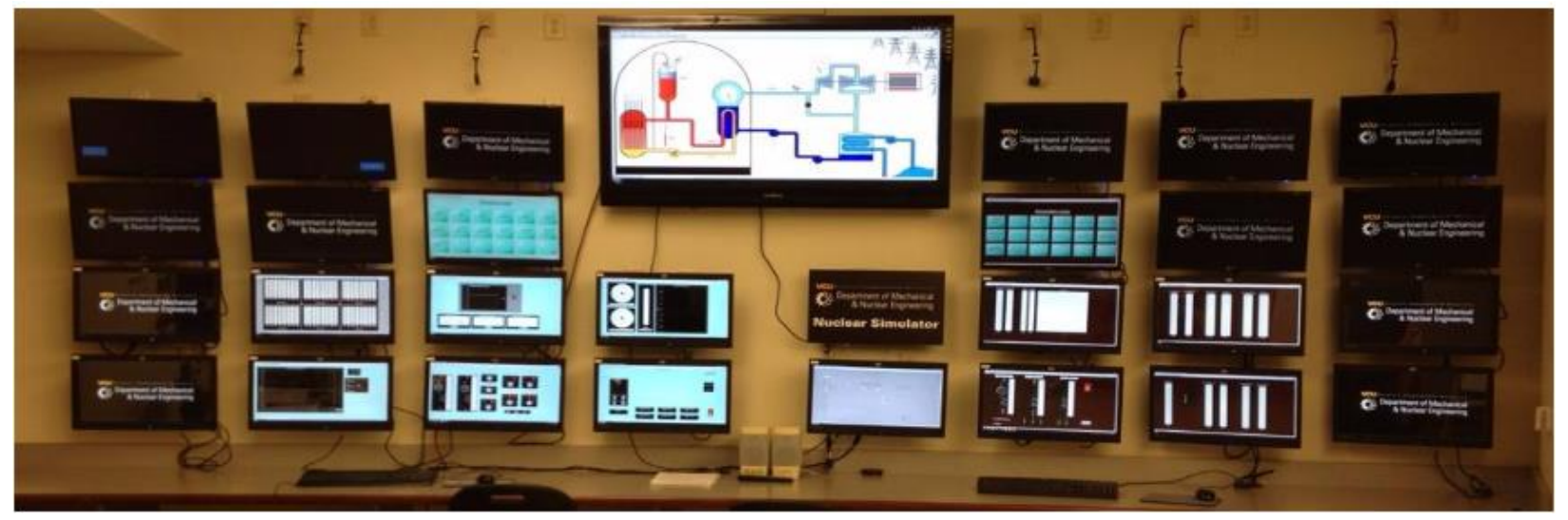

Figure 5: Year two of the nuclear simulator built for safety training and educational purposes. This project continues to be used for demonstrations during school visits.

These projects demonstrated that diversity will work if the person in charge is aware of what everyone brings to the table and if there is more than one advisor and all the advisors work together to develop realistic but challenging team expectations for all the students.

Uneven participation or the perception of uneven participation: This could be due to varying degrees of ability between the students, an uneven sense of responsibility or personal perception of excellence. At other times, there is the perception of uneven participation because of a lack of awareness of the different talents and types of contributions others bring to the table. In addition, collaboration does not mean that they work on all aspects of the project together. The role of the adviser here is to be very specific about expectations so that students can distribute the workload based on their individual or collaborative skills and are enabled to work both independently and together.

The first concept we focus on is that of $100 \%$ responsibility. In other words, no matter how many people are on a team, all team members are $100 \%$ responsible for the outcome of the project. This is a hard concept for students to understand, primarily because their perception of success is inextricably tied to the grade they receive, and they work on the premise that they will all receive the same grade. We are very clear up front that this is not the case, and we outline to all the students how we will differentiate them. While we do use self- and peer evaluations so that students gain experience in this skill, this is not the primary tool we employ to gauge student participation. For a while, self and peer evaluations were used to promote "good behavior" among team members, but students would typically give each other good evaluations even when it was clear to the advisers that there was trouble in the team and that there were team members that did not pull their own weight. 
A better model is to ensure that a different team member reports out in the weekly meetings with the advisor(s), and that they all report out an equal number of times. Students are allowed only one unexcused absence for these meetings; any other absences need to be excused. The person reporting out is responsible for being informed on all aspects of the project, and the advisers direct all questions to this person. The presentation is graded, with the reporting team member receiving the earned grade. Other team members are responsible for recording the meeting minutes and submitting them to the advisor(s) within a few days of the meeting for grade as well. In addition, the team is required to set independent weekly meeting times to discuss, work on the project and develop "next steps". Individually or as a team, a minimum of six hours a week needs to be spent on the project.

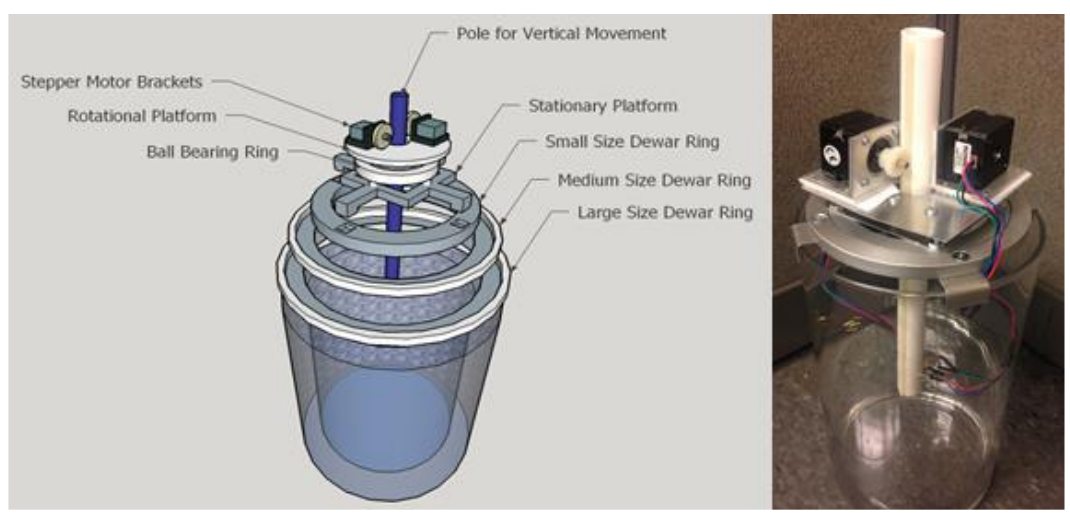

Figure 6: Automated Magnetic Field Scanning System to map the magnetic field inside a liquid helium dewar used to test superconducting RF cavities. Conceptual drawing and prototype.
A good example where this process was helpful in keeping a relatively dysfunctional team on task is the "Automated Magnetic Field Scanning System" project (Figure 6). The team had wanted to engage a mechanical engineering student to help them with their physical design and implementation. This was not achieved; thus instead, they were required to train in the machine shop and to design and build everything themselves. In addition to

initially resenting this necessity, one of the team members lost interest in the project half-way through and the others were hard pressed to let go of their resentment and keep on working without regard to their disengaged colleague.

In the end, an interesting dynamic was created within the group. The student who was the most opposed to taking the machine shop training course ended up enjoying it, received the highest marks from the instructor, and took on in its entirety the physical design and implementation of the magnetic field scanning system prototype (to be used inside a liquid helium dewar). Of the other two students, one maintained a high level of engagement throughout, but expressed a high degree of frustration with his colleague who was disengaged. This affected his performance, but because he was allowed and even encouraged to vent his frustration, the advisors were able to refocus him on the task at hand. He then worked effectively on the control system. This had the effect of re-energizing the team's other colleague, who stepped up to contribute significantly to the project.

The third colleague also took on the significant role of writing up the final report. It is usually not a good idea for the non-performer to write the final report, but in this case, because this particular student was re-motivated early enough, he did a good job capturing the key aspects of the project and writing a good final report. More importantly, the team was able to finalize their 
prototype and demonstrate it at the Capstone Expo. Due to this success, the team was able to project their enthusiasm and earned high marks from the ECE Industry Advisory Board and from their industry sponsor.

For this team, reiterating often the idea of $100 \%$ responsibility was very important. It kept the high performers engaged and on task and re-energized the one team member in time to lead to good outcomes. Reviewer comment: "Excellent working prototype ..."

Uneven skills: In this scenario, students come into a team exhibiting significantly different academic achievements. This case usually leads to a combination of behaviors similar to those exhibited by highly diverse teams as well as teams whose members exhibit uneven motivation. This situation can be managed by applying all the methodologies outlined in the first two cases.
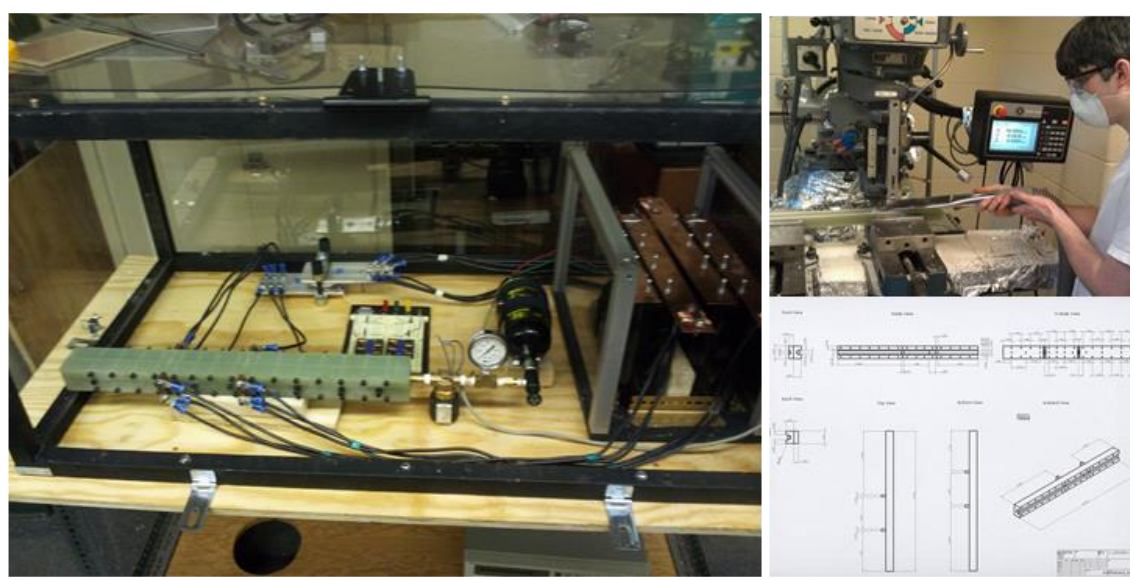

Figure 7: Design and implementation of the electromagnetic Launch System. Maximum exit speed achieved was 90 feet per second.
An example of a team whose members exhibited an uneven level of skills as well as motivation is the "Electromagnetic Launch System" project (Figure 7). This kind of team can succeed with the right level of involvement of the advisors. As always, the role of the advisor is to set expectations and enable the students to discover solutions to all the problems that arise whether these are team

dysfunctions or technical challenges. In this scenario, each team member was independently held to account for their participation. In addition, clear roles were defined and all students learned the fundamental concepts relevant to this project - such as electromagnetics principles, circuit simulations, machine shop training, Solidworks, and controls. The student with the strongest degree of engagement took on the role of team lead but all students self-selected into their primary responsibility for the project. As with all teams, students were expected to go through a full design cycle - conceptual proposal, design and simulation, construction planning using SolidWorks and circuit/device analysis using Multisim, LabView, MATLAB or other (relevant) simulation software. Once these stages are complete, the students implement their designs and build a working prototype. This team was very successful, both in establishing a solid team dynamic as well as in terms of meeting and exceeding design goals.

\section{Lessons learned: Components of a systematic approach to Capstone Advising}

In conclusion, regardless of team dynamics, relative student engagement or level of achievement at the onset of the project, we have found that teams are successful and students gain confidence, 
independence and self-confidence when the advisors apply a systematic approach to the challenge of mentorship. To summarize, this approach involves the following components:

1. Advisors lead the team by setting clear expectations, both for the team and the individual team members. It is made clear that each member of the team is $100 \%$ responsible for the project outcome.

2. Advisors provide a syllabus and a mechanism for regular feedback to the team and to individual team members. Feedback should be given along professional lines - in the form of performance evaluations, not necessarily through goal-defined rubrics, but through learner-trait defined rubrics.

3. All teams are required to follow systematic design methods. They start with the relevant research, propose and sketch out a conceptual design, simulate their proposed design, prepare a components list with a proposal for funding. Lastly, they prototype and optimize their design.

4. Advisors also provide training and feedback on team communication skills.

a. Presentations: Weekly presentations need to be concise, quantitative and effectively communicate team progress. In addition, all teams develop a fiveminute "elevator pitch" for their project to be used for the funding competition run by the school. Teams also give midterm and final presentations (40 min) each semester.

b. Reports: Midterm progress reports in both semesters, design report at the end of the first semester and Final report at the culmination of the project. For working prototypes, operation manual is also required. Advisors provide written feedback to students as they are writing and developing their reports so their understanding develops throughout the semester.

c. Final poster: Advisors also provide feedback on the poster and help students develop their skill in putting together effective posters.

5. Students self-assemble in terms of choosing a leader and selecting which technical aspects of the project they will primarily be responsible for. All students are expected to contribute (in varying degrees) to all aspects of the project.

6. Dysfunctional behavior is dealt with collaboratively with all team members. Disruptive or negative attitudes are dealt with directly and discussed openly with the whole team.

7. Advisors initially assist with the high-level timeline and train the students to adjust the timeline and add details as their understanding of their project matures. The teams are expected to keep a dynamic Gantt chart.

8. Advisors meet with the team once a week until a rhythm of consistent goal attainment is reached. Usually, by the second semester, a pattern of bi-weekly meetings can be set, 
with weekly reporting sessions being replaced by prototype demonstration and report and poster preparation and critiquing.

9. All eligible teams are encouraged to participate in the funding competition run by the school and funded by a benefactor. Winning teams are selected by volunteers from industry. This provides training and practice in a mode that is mostly unfamiliar to students.

10. Students are responsible for maintaining a timeline, which they continuously refine throughout the capstone experience. They are also responsible for brainstorming, holding independent meetings, working together and independently to realize their ideas and developing and building a prototype of their design. They are also responsible for developing their theoretical understanding of all aspects of their project, and identifying and using any tools that can help them implement their design. All teams follow a design cycle that follows the research-brainstorm-design-simulate-build-review-optimize paradigm.

When there are no conflicts: Before we conclude, it should be mentioned that there also exist teams with minimal to no conflicts during the capstone experience. For example, we have worked with a unique team of students on the "Linear Rotary Motor" project (Figure 8). All team members were transfers from the community college system and had served in the military. Their project was to design and build a motor that provided both linear and rotational motion. In spite of the fact that this team possessed all the characteristics we have mentioned in this article, they still exhibited varying degrees of interest in completing all project requirements: they did not appreciate - at least initially - the need to simulate their design (see Figure 9), had different levels of skills and experienced personal challenges during the academic year. In spite of this, the team never actually exhibited any dysfunctional behavior. They operated independently on the aspects of the project in which they were directly interested and completed efficiently and effectively all aspects of the projects required by the advisors, even if they did not intuitively appreciate the need to do so. This project won first prize in the ECE category and was accomplished with minimal team issues, even though it met with quite significant technical and mechanical challenges. We have not had the opportunity to test this theory, but it seemed that the maturity of the students, possibly coupled with their military training, made them better prepared to accept any non-ideal team dynamics or technical and personal difficulties they faced during the execution of the project.

\section{Results}

In terms of positive team results, we can report that all of our teams have received high ratings from our Industry Advisory Board (IAB) evaluators participating in the Expo. In the past four years that we mentored teams:

1. All teams that were eligible to participate in the grant funding competition were awarded at least $85 \%$ of their proposed funding. Only $25 \%$ of the teams participating in the competition are awarded any funding. 
2. Our teams won their category's Capstone award in two out of the last four years we participated as mentors. In 2016, two of our teams won top honors - one in the ECE category and the other in the Multidisciplinary category.

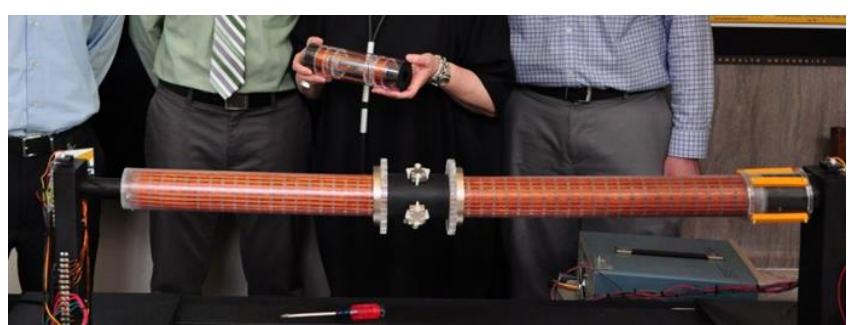

Figure 8: Final prototype of the linear-rotary motor. The payload could move along the length of the motor, it could rotate in place or it could describe a helical path down the length of the motor. In addition, the students could program the motor to move to any point and any angle of rotation using feedback from optical proximity and rotary sensors.

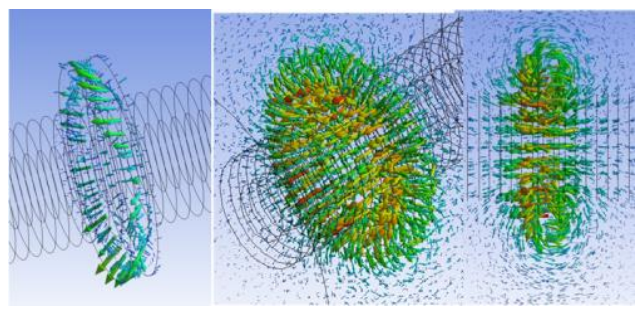

Figure 9: Simulation of electromagnetic fields around the vertical and perpendicular coils of the linear-rotary motors.

3. Our average team IAB scores in the ABET categories $\mathrm{c}, \mathrm{d}, \mathrm{g}, \mathrm{h}$, and $\mathrm{j}$ are always above the average of all other ECE teams, as can be seen in Figure 10. In all these capstone relevant categories, a consistently higher level of performance has been observed over the years, with some exceptions in the $\mathrm{h}$ (global, economic, environmental, societal impact) and $\mathrm{j}$ (knowledge of contemporary issues) outcomes. Even in these $\mathrm{h}$ and $\mathrm{j}$ categories, the scores earned by our teams are higher than $80 \%$, but it is important to continue to develop these and other $21^{\text {st }}$ century skills in our students [8] [9] [10]. It is important to note that the other ECE teams did not employ a systematic advising approach. However, almost all ECE teams score high in all these ABET categories as all ECE faculty work hard to ensure the teams are successful and that we develop students' soft skills as well as their technical skills. While it is not possible to isolate the effect of each individual rule of engagement employed, we believe that the overall systematic approach described here is responsible for improved success of the projects.

\section{Conclusion}

The methods proposed here require medium to high level of involvement on the part of the faculty mentor, primarily in the first semester of the capstone experience. Once a rhythm is established and the research, design and simulation stage is complete, teams attack the implementation phase of the project with confidence and, barring major technical concerns or a personal situation that interferes with established team dynamics, the spring phase of the project is completed with a much lower level of time commitment on the part of the advisor. What seems to help all the teams significantly is to see that the advisor is engaged and invested in their success. The authors have collaborated on some projects and advised 
independently on others, but invariably follow the same fundamental process and jointly or independently lead their teams to successful outcomes, including in the past year, both earning top honors - one in the ECE category and the other in the Interdisciplinary category (in a team comprised of Electrical and Chemical Engineering students). In addition, both advisors' teams were recipients of the funding award in the 2015-16 year as well as in the 2016-17 year. All teams successfully implemented working prototypes of their designs and earned high marks from industry advisors who participated in the Expo.

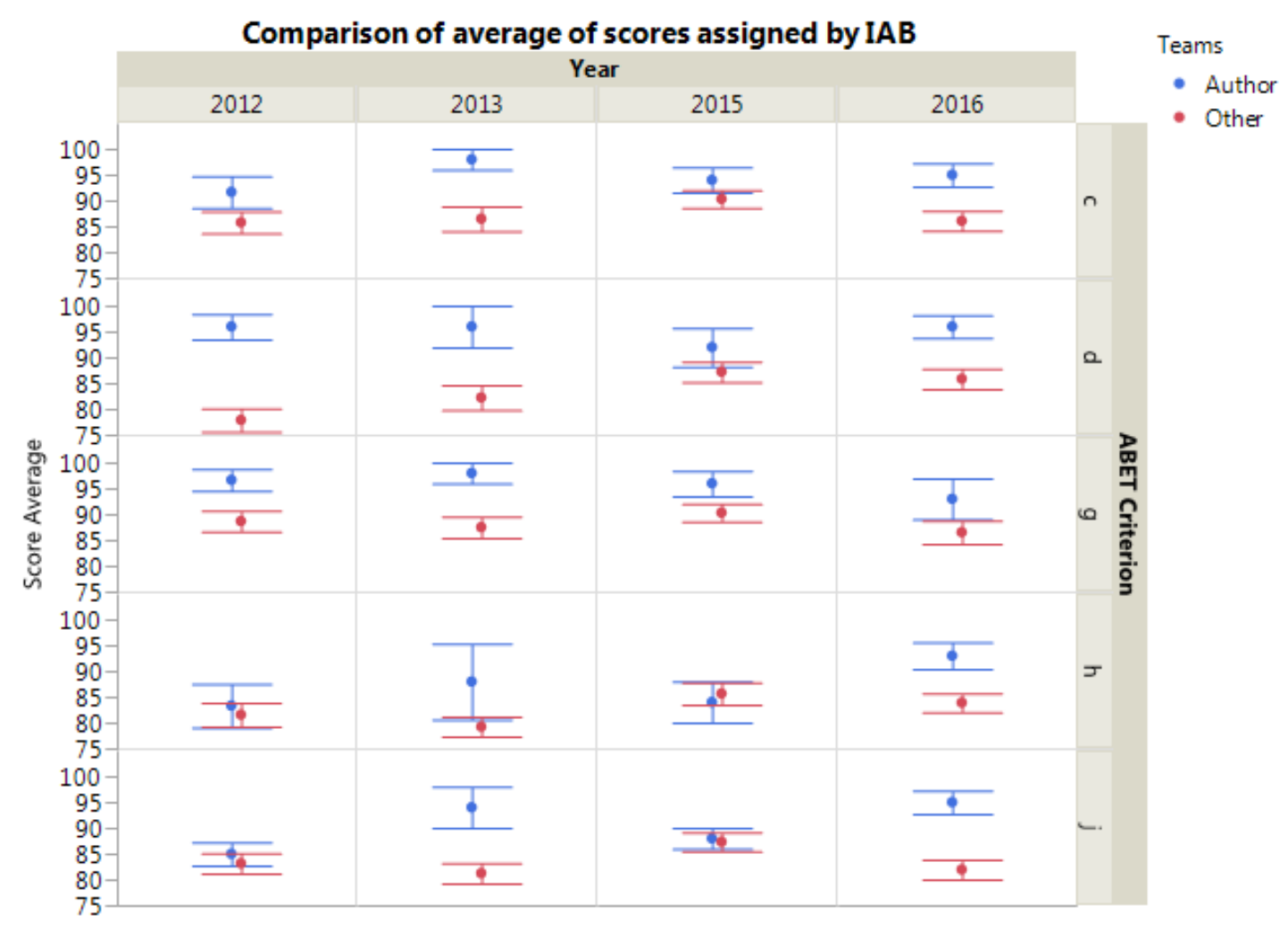

Figure 10: Author team averages (blue) with standard errors for capstone categories $c, d, g, h$, and $j$ in years 2012-2016 (authors did not participate in a Capstone project in 2014) compared against the averages of all other ECE teams (red). Note that in all categories relevant to capstone, our teams score higher than average. 


\section{References}

[1] N. Donofrio, J. Spohrer and H. S. Zadeh, "MJA Viewpoint," 5 March 2010. [Online]. Available: http://www.ceri.msu.edu/wp-content/uploads/2010/06/A-Case-for-TShapedProfessionals-20090907-Hossein.pdf. [Accessed 21 2017].

[2] "Education Reform," 258 2016. [Online]. Available: http://edglossary.org/21st-centuryskills/. [Accessed 2612 2017].

[3] R. R. a. O. P. J. McCrae, "An Introduction to the Five-Factor Model and Its Applications," Journal of Personality, vol. 60, no. 2, pp. 175-215, 1992.

[4] B. o. Directors, "Criteria for Accrediting Engineering Programs," 1 November 2014. [Online]. Available: http://www.abet.org/wp-content/uploads/2015/05/E001-15-16-EACCriteria-03-10-15.pdf. [Accessed 2016].

[5] P. A. Linley, K. M. Nielsen, R. Gillett and R. Biswas-Diener, "Using signature strengths in pursuit of goals: Effects on goal progress, need satisfaction, and well-being, and implications for coaching psychologists," International Coaching Psychology Review, vol. 5, no. 1, pp. 6-15, March 2010.

[6] K. L. Tonso, "Teams that Work: Campus Culture, Engineering Identity, and Social Interactions," Journal of Engineering Education, pp. 25-37, January 2006.

[7] J. Trevelyan, "Technical Coordination in Engineering Practice," Journal of Engineering Education, pp. 191-201, July 2007.

[8] L. E. Velazquez, N. E. Munguia and M. A. Romo, "Education for a Sustainable Development: The Engineer of the 21st Century," European Journal of Engineering Education, vol. 24, no. 4, pp. 359-370, 1999.

[9] J. Ingham, "Closing the talent management gap," Strategic HR Review, pp. 20-23, Mar/Apr 2006.

[10] K. Khalaf, W. Newstetter and H. Alsafar, "Globalization of Problem-Driven Learning: Design of a System for Transfer across Cultures," in The 4th International Research Symposium on Problem-Based Learning (IRSPBL), 2013. 